\title{
Psychological distress and user experiences with health care provision in persons living with spinal cord injury for more than 20 years
}

\author{
VM Jakimovska ${ }^{1,2}$, E Kostovski1,2, F Biering-Sørensen ${ }^{1,3}$ and IB Lidal ${ }^{1}$
}

\begin{abstract}
Study design: Descriptive cross-sectional and retrospective study.
Objectives: To gain more insight into the long-term health status in persons with traumatic spinal cord injury (SCl), especially perceived psychological distress as well as self-reports of utilization of healthcare services.

Setting: Sunnaas Rehabilitation Hospital, Norway.

Methods: In total, 147 persons with SCl were examined for more than 20 years and interviewed (in 2004/2005) using a self-administrated questionnaire and General Health Questionnaire (GHQ-20). Descriptive statistics and a logistic regression analysis were conducted to identify variables associated with psychological distress.

Results: Most participants had received SCl follow-up health services at least once after initial rehabilitation; $34 \%$ were satisfied, $51 \%$ neutral and $18 \%$ unsatisfied with the health services provided. Concerning psychological distress, 34 persons were cases according to the GHQ-20. The cases did not differ from non-cases concerning demography, time since injury, injury aetiology, injury severity, marital status or employment status. The regression analysis revealed that cases were associated $(P<0.05)$ with more use of $\mathrm{SCl}$-specific follow-ups.

Conclusion: In a 20+ years' post-injury SCI population, psychological distress is common and associated with the use of follow-up services. The varying satisfaction of people with $\mathrm{SCl}$ about healthcare services is notable, as is the finding that $20 \%$ of people with paraplegia did not use specific $\mathrm{SCl}$ follow-up services. The experiences of people with $\mathrm{SCl}$ with healthcare services need further investigation, and there is also a need for studies that examine the effects of interventions aimed at improving services and patient satisfaction.
\end{abstract}

Spinal Cord (2017) 55, 864-869; doi:10.1038/sc.2017.29; published online 21 March 2017

\section{INTRODUCTION}

A spinal cord injury (SCI) influences on all the domains described in the International Classification of Functioning, Disability and Health (ICF) framework, ${ }^{1}$ both in the short- and in the long-term. Long-term survivors with SCI face complex and lifelong challenges related to impairment, activity, participation and quality of life (QOL). As during the first post-injury year, complications in the longer term may increase the severity of the disability, decrease the QOL and lead to lower participation such as unemployment. ${ }^{2}$ The lifelong high risk of medical complications may interfere with physical, mental and social well-being, and may often lead to re-hospitalizations and frequent usage of health services. ${ }^{3}$

A scoping review of 21 articles by McColl et al. ${ }^{4}$ showed that adults with long-term SCI identify family physicians as their regular doctors; furthermore, it showed that $63 \%$ of the participants have often contact with a SCI specialist. McColl et al searched for studies within primary care; however, no relevant studies from Scandinavia were identified. Although being frequent users of health services in general, ${ }^{5}$ the evidence from the review indicates that the information needs of people with SCI are poorly met $^{4}$ and that regular follow-up by specialized teams and annual comprehensive health examination are needed. In a recent primary study, Stillman et al. ${ }^{6}$ studied healthcare utilization during the past year, barriers encountered when accessing healthcare facilities and receipt of routine care and preventative screenings. ${ }^{6}$ Stillmann et al have similar conclusions as McColl et al that properly trained staff with a proactive approach in preventative care recommendations is needed in assisting individuals with mobility disabilities.

Psychological distress has been well documented in the initial rehabilitation process after an SCI. ${ }^{7-9}$ It is very important for the initial rehabilitation process and for the later community reintegration to manage psychological distress in persons with SCI. Our experiences are that, persons with SCI are vulnerable to psychological discomfort that interferes with activities of daily living even in the long-term. It is important to identify factors that might influence on psychological well-being in persons living decades with an SCI, to help improve the overall understanding of these persons' situation and to be able to give better advices concerning follow-up healthcare routines. The General Health Questionnaire (GHQ) has been developed to detect minor psychiatric disorders in the general population within the community

${ }^{1}$ Sunnaas Rehabilitation Hospital, Science Department, Nesoddtangen, Norway; ${ }^{2}$ Faculty of Medicine, Department of Physical Medicine and Rehabilitation, University of Oslo, Oslo, Norway and ${ }^{3}$ Clinic for Spinal Cord Injuries, Rigshospitalet, University of Copenhagen, Copenhagen, Denmark

Correspondence: Dr E Kostovski, Sunnaas Rehabilitation Hospital, Science Department, Bjørnemyrveien 14, Nesoddtangen 1450, Norway.

E-mail: Emil.kostovski@sunnaas.no

Received 13 September 2016; revised 20 February 2017; accepted 23 February 2017; published online 21 March 2017 
or in nonpsychiatric clinical settings such as primary healthcare or general medical out-patients. ${ }^{10-14}$ Thus, the purpose of this study was to gain more insight into the long-term health status in people with traumatic SCI living in Norway, especially their perceived psychological distress by GHQ as well as self-reports of healthcare services utilization.

\section{MATERIAL AND METHODS}

\section{Inclusion, setting and the data collection procedures}

The inclusion criteria were as follows: traumatic SCI, admitted for initial rehabilitation at Sunnaas Rehabilitation Hospital (SunRH) between 1961 and 1982. SCI rehabilitation has been performed at SunRH since 1961, and from 1973 onward the management of SCI has been based on a multi-professional approach. In Norway today, traumatic SCI is treated in one of the three highly specialized spinal units: Haukeland University Hospital in Bergen, St. Olav University Hospital in Trondheim and Oslo University Hospital/SunRH. The latter is the largest spinal unit with a catchment area of about 2.9 million people (55\% of the Norwegian population).

Invitations were sent by mail to 237 eligible persons to ask for their participation in the study. The data collection, which took place in 2004 and 2005, has been described previously. ${ }^{15,16}$ In short, participants answered self-administered questionnaires and were interviewed face-to-face as well as clinically examined. All interviews and examinations were conducted by the same person.

\section{Measures}

Demographic information (gender, age at injury and age at the time of the study) and injury aetiology were collected from medical records and information on marital status, education and employment as part of a structured interview. Marital status was dichotomized into 'married/cohabitant' versus 'single', and employment status was dichotomized into 'employed' (part-time or full-time paid work) and 'not employed' (students, unemployed, homemakers). All participants were asked to indicate their present main health problem (open-ended question). ${ }^{16}$ We merged health problems into six categories reflecting the most frequent answers. Injury aetiology was grouped according to the International Spinal Cord Injury Core Data Set. ${ }^{17}$ A questionnaire on follow-up routines was filled in by the study physician in collaboration with each participant. The questionnaire was prepared for the current study and included questions on participant's healthcare utilization and satisfaction with provided healthcare during the last five years (Supplementary Appendix I). The questionnaire was developed using evidence-based research and clinical SCI rehabilitation experience.

A standardized clinical examination took place and included a neurological assessment according to the International Standards for Neurological Classification of SCI (ISNCSCI), including the American Spinal Injury Association (ASIA) Impairment Scale (AIS). ${ }^{18,19}$ We divided the participants into the following neurological subgroups: C4 AIS A, B or C (i); C5-8 AIS A, B or C (ii); T1-S5 AIS A, B or C (iii), and AIS D and E at any injury level (iv) based on recommendations from DeVivo et al. ${ }^{20}$

The GHQ-20, a self-report instrument, was used to assess emotional wellbeing. The GHQ-20 consists of 20 multiple choice questions screening for life satisfaction and minor psychiatric disorders. ${ }^{14,21,22}$ The GHQ-20 has shown acceptable psychometric quality and has been translated into Norwegian. ${ }^{14,22}$ The items are scored on a four-point response scale ranging from 'better than usual' (score $=0$ ) to 'much worse than usual' (score $=3$ ) in positively phrased items or 'less than usual' (score $=0$ ) to 'much more than usual' $($ score $=3$ ) in negatively phrased items. A possible sum score range from 0 to 60 . In the current study, we used the alternative scoring procedure, which can be used for identifying cases. ${ }^{23}$ The four response categories are treated as a binary response scale with scores 0 or 1, giving a possible maximum score of 20. A cutoff point for case identification is set between 3 and 4 in the GHQ-20.

\section{Statistical analyses}

The statistical analyses were performed with SPSS version 22 (Chicago, IL, USA). Descriptive statistics included proportions, ranges, means and s.d., together with simple tests, including Fishers-exact test and $X^{2}$ tests to compare categorical variables and $t$-tests, and Mann-Whitney $U$ tests to compare continuous variables. We performed a binary logistic regression analysis with GHQ-20 cases versus non-cases as the dependent variable, to study factors that might be associated with psychological distress. First, we tested independent variables believed to have impact on psychological distress, in a univariate regression model. Variables that explained a similar relationship were excluded. The independent variables were selected based on judgement and previous research. ${ }^{15}$ Age, gender and level of injury (three groups - i+ii, iii and iv) were included with the use of the Enter method; six more variables, with a $P$-value equal to or lower than 0.25 in the univariate regression model, were included with a backward likelihood Ratio (LR) method. Values are reported as odds ratios (OR) with intercept (B) with standard error and 95\% confidence intervals (CIs). We considered $P$-values less than 0.05 to indicate statistical significance. $P$-values $<0.1$ were considered as a tendency.

\section{Statement of Ethics}

We certify that all applicable institutional and governmental regulations concerning the ethical use of human volunteers were followed during the course of this research. The research was approved by The Regional Ethics Committee in Oslo, Norway.

\section{RESULTS}

\section{Characteristics of the study participants}

Table 1 presents the characteristics of the 147 who answered the GHQ-20, out of 165 persons from the total study sample. The table also shows cases and non-cases as scored with the GHQ-20, and the statistical comparison between the two groups. There was a tendency towards difference between cases and non-cases for level of injury; $23 \%$ of the cases were people with tetraplegia versus $40 \%$ of the non-cases.

\section{Psychological distress}

A total of 34 persons were classified as cases with the GHQ-20. Table 2 shows the GHQ-20 results in the four neurological subgroups. Table 3 shows the results of the logistic regression-that is, the association between different variables on GHQ-20 cases and non-cases. Our model explained $12.5 \%$ of the relationship between the two GHQ-20 groups (see Table 3 ). The regression analysis revealed that cases were associated with the use of SCI-specific follow-ups $(P=0.039)$. A statistical significant association $(P=0.048)$ was also seen with the variable psychological issues as a main health problem; however, the confidence interval was very broad. Furthermore, the regression results indicate a tendency towards cases reporting pain as a main health problem $(P=0.050)$. Our model showed insignificant results for age, gender and neurological subgroup as well as for self-reported spasms, bone fractures and ulcers experienced during post-injury years until follow-up.

\section{Follow-up routines}

Table 4 presents the participant's $(n=165)$ self-reported utilization of healthcare services. The majority confirmed that they had been to a SCI follow-up routine service at some time after initial rehabilitation. Time since the last SCI-related follow-up varied from within the past year and up to 38 years ago, with a mean of 12 years. Most participants perceive that their general practitioner (GP) has a fairly good knowledge concerning the SCI, and visit the GP when perceived necessary. Most of the participants had seen a specialist doctor within the last 5 years, and most commonly a neurologist or orthopedic surgeon. The study population reported that they relatively often saw an occupational therapist and a physiotherapist, but more seldom were in contact with nurses and psychologists. We also asked for 
Table 1 Characteristics of all participants

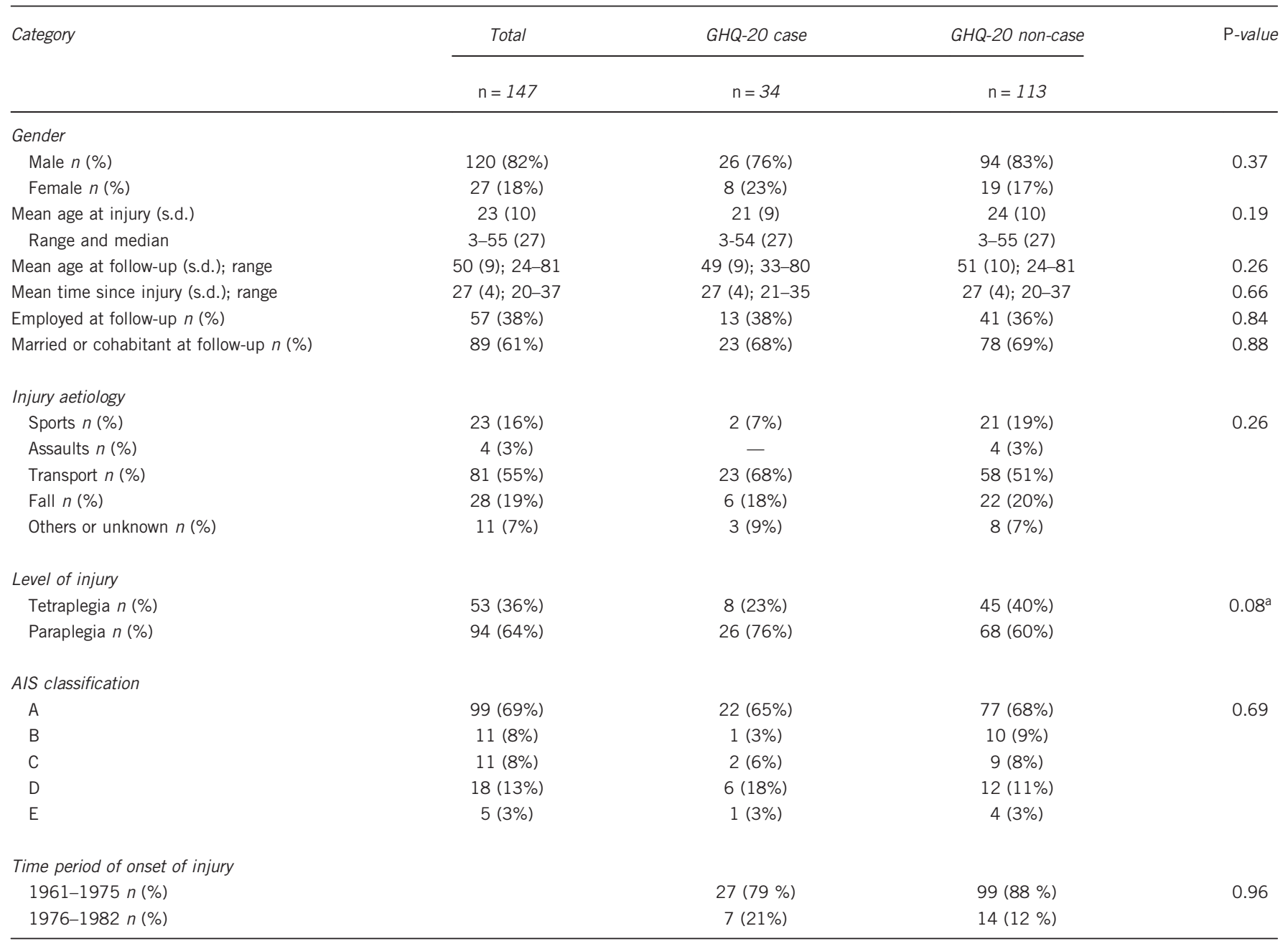

Abbreviations: AIS, ASIA Impairment Scale; ASIA, American Spinal Injury Association.

Demographic and injury-related characteristics of all participants were divided by the General Health Questionnaire version 20 (GHQ-20) cases and non-cases. Values are given in absolute numbers, percentages, mean (s.d.) and/or range within the group.

a $P$-value: $X^{2}$ or Fisher's exact test used where appropriate.

Table 2 General Health Questionnaire version 20

\begin{tabular}{lccc}
\hline & & Level and severity (AlS classification) of spinal cord injury \\
\cline { 2 - 4 } & $C 4 A B C(\mathrm{n}=3)$ & $C 5-C 8 A B C(\mathrm{n}=34)$ & $T 1-S 5 A B C(\mathrm{n}=77)$ \\
\hline $\begin{array}{l}\text { GHQ-20-sum }{ }^{\mathrm{a}} \text { range; mean (s.d.) } \\
\text { Cases/non-cases }\end{array}$ & $\begin{array}{c}0-11 \\
1 / 2\end{array}$ & $\begin{array}{c}0-9 ; 1.2(2.2) \\
4 / 30\end{array}$ & $0-19 ; 2.6(4.4)$ \\
\hline
\end{tabular}

Abbreviations: AIS, ASIA Impairment Scale; ASIA, American Spinal Injury Association; GHQ-20, General Health Questionnaire version 20.

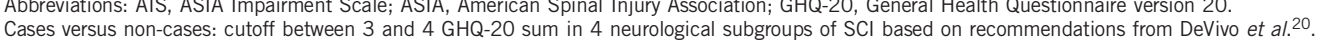

aBinary response scale with scores 0 or 1 , values are given in range, mean and s.d.

consultation with alternative medicine practitioners, who seems to be rarely visited by this group of Norwegian long-term survivors with SCI. The overall satisfaction with the provided health services varied; $34 \%$ were satisfied, $51 \%$ neutral and $18 \%$ unsatisfied with the services.

\section{DISCUSSION}

The purpose of this study was to investigate aspects of long-term health status in persons with traumatic SCI through measuring their level in terms of psychological distress and self-reports of utilization of healthcare service. The important findings from this study are that psychological distress (GHQ-20 cases) is common decades post injury. We found GHQ-20 cases to be associated with utilization of SCI-specific follow-ups versus not. Furthermore, there was a tendency towards an association between cases and the variable pain as a main health problem. Most of the participants have received SCI follow-up health services at least once, but their overall satisfaction with the provided health services varied. 
Table 3 Logistic regression model

\begin{tabular}{lcccccc}
\hline \multirow{2}{*}{$\begin{array}{l}\text { Variables associated with } \\
\text { psychological distress }\end{array}$} & \multicolumn{6}{c}{ Logistic regression results } \\
\cline { 2 - 6 } & $B$ & s.e. & P-value & $\begin{array}{c}\text { Coefficients } \\
\text { (OR) }\end{array}$ & $\begin{array}{c}\text { Confidence } \\
\text { intervals }\end{array}$ \\
\hline Age & & & & 0.99 & 1.0 & $0.95-1.05$ \\
Gender & 0.00 & 0.24 & 0.99 & 0.67 & $0.24-1.91$ \\
Any level AIS DE & -0.39 & 0.53 & 0.47 & - & - \\
T1-S5 AIS ABC & - & - & 2.90 & -1.30 \\
C4-C8 AIS ABC & -1.05 & 0.67 & 0.16 & 0.35 & $0.09-1.30$ \\
& -0.48 & 0.54 & 0.37 & 0.62 & $0.22-1.77$
\end{tabular}

Never been to control

$\begin{array}{llllll}\text { Yes/No } & -1.76 & 0.85 & 0.039^{a} & 0.17 & 0.03-0.91\end{array}$

Psychological issues as worst health concern

$\begin{array}{llllll}\text { Yes/No } & 2.78 & 1.40 & 0.048^{\mathrm{a}} & 16.06 & 1.03-250.67\end{array}$

Pain as worst health concern

$\begin{array}{llllll}\text { Yes/No } & -1.07 & 0.54 & 0.050 & 0.34 & 0.12-0.99\end{array}$

Do you have spacticity or spasm

Yes/No

$0.990 .63 \quad 0.12$

2.68

$0.77-9.29$

Abbreviations: AIS, ASIA impairment scale; ASIA, American Spinal Injury Association Impairment Scale; B, intercept; OR, odds ratio.

Variables included in a multivariate regression model.

a $P$-value $<0.05$. Model summary: Cox and Snell $R^{2}: 0.125$

Our material does not include psychological assessments 0-20 years post injury to compare the development over time, but in a previous paper we showed that pre-injury presence of psychiatric disease and/or a history of alcohol or substance abuse were among risk indicators for premature death. ${ }^{24}$ The results based on a study population living with SCI for more than 20 years probably reflect healthier persons and psychological stability analogous to survival effects. As such, the results from the current study should preferably be compared with other 21-year plus findings.

Among the long-term survivors of 147 persons with SCI, 23\% were assessed as psychological distressed 21-35 years post injury, according to the GHQ-20. This result is comparable to a recent study by Kennedy et al., ${ }^{25}$ indicating that $23 \%$ of their cohort $(n=22)$ met the criteria for moderate depression on the Beck Depression Inventory (Beck \& Steer, 1987). Kennedy et al. ${ }^{25}$ suggested that participants who scored highly on depression at week 12 were more likely to still score highly 21-plus years later.

A study from USA found pain and depression to be correlated to more healthcare utilization in SCI veterans (years since injury (range); 5-35 years $)^{26}$ and Noonan et al. ${ }^{27}$ found multimorbidity and healthcare utilization to be interrelated and associated with lower health status, which in turn is associated with lower quality of life in persons living with their SCI for more than 1 year (years since injury (mean (s.d.) 18 (13) years)). Adriaansen et al. ${ }^{28}$ found lower quality of life in persons living with their SCI for more than 10 years (mean 22 years) to be associated with musculoskeletal pain, ulcers, spasticity and constipation. Siddall et al also found pain to impact on spiritual well-being in people with long-term SCI. ${ }^{29}$ In our study, psychological distress was not associated to age, gender, employment or marital status, which have also been shown in a study by Migliorini et al. ${ }^{30}$ in people with a long-term SCI (time since injury (range) 7-51). Distress in our cohort was independent of age at injury and time since injury, within the range of 21-35 years post injury. Although not significant, a slightly higher percentage of persons with less disability (AIS D and E) were GHQ-20-cases compared to persons with more serious neurological deficits. We think this is an interesting result. An explanation might be the development of adaptive strategies over time that allows people with more serious neurological deficits to cope with complications and deterioration in function ${ }^{31}$, whereas people with a less disability, have higher expectations for their lives, and experience distress. Hartkopp et al. found people with SCI Frankel E (similar to AIS E) to commit more suicides ${ }^{32}$ than people with more severe SCI (Frankel A-D).

The utilization and experiences with healthcare services in a sample of community-dwelling persons with SCI in Norway are interesting in many ways. The information indirectly indicates health issues among these persons and also some of the load they face in addition to everyday challenges. ${ }^{33}$ It is interesting that persons with SCI AIS D and E seem to have approximately the same pattern of healthcare service utilization as those with more severe disability when it comes to consulting a neurologist and orthopedic surgeon. Our data do not include reasons for service utilization, however, we speculate that pain may be a frequent cause since many pointed to pain as their main health problem. ${ }^{16}$ The SCI follow-up services in Norway mostly involve specialists in physical medicine and rehabilitation, but the spinal units also have neurologists, and one of the units is based in a neurologic department. Twenty percent of the persons with paraplegia indicated that they never go to SCI-specific follow-up; however, they might have recollected these follow-up visits as neurologistsconsultations when questioned about specialist consultations or the GP have indeed recommended a consulting neurologist instead of a specialist in physical medicine and rehabilitation. The GP is the first line when meeting the health system, and most persons in our sample replied that their GP knows about their SCI and $~ 50 \%$ report that their GP has good knowledge of it.

If we compare our cohort to similar group of persons with an injury more 20+years ago in UK, most visits there are for skin problems and urinary tract complications. ${ }^{34}$ In another study by Hamilton et al. consisting of 142 participants with a SCI for more than 12 months, almost all respondents had a healthcare visit in the past 12 months with primary-care physicians, SCI physiatrists and urologists being the most utilized. The majority were satisfied with their primary-care physician, and SCI physiatrist and individuals who did not visit an SCI physiatrist were significantly more likely to live in a rural area among more. ${ }^{35}$ In Australia, one study found longer travel distances also to be predictors of less physician/specialty clinic and physiotherapy utilization in people with SCI, $4-5$ years after injury. ${ }^{36}$ Long distances to healthcare utilities is very common in rural areas of Norway and could explain low use of SCI-specific follow-up in parts of our study group of people with long-term SCI.

By 2004, very few from our study sample did seek complementary and alternative medicine (CAM) services. In 2014, 74\% of a Swiss cohort (median 20 years post SCI) reported the use of CAM services, most often for pain or urinary tract infections. ${ }^{37}$ The data from the general Norwegian population in 2008 show that $16 \%$ use CAM, which is a $50 \%$ increase during a 10 -year period. ${ }^{38}$ The low utilization of CAM in our study sample reflects that of the general population, and might be because access to healthcare is easy and inexpensive in Norway. Compared to the Swiss sample from 2014, we also need to point to time trends.

In previous papers, it has been commented on the representativeness of the study group, ${ }^{15}$ including the non-responder limitations, although our response rate was fairly high. It could be that individuals with more severe conditions may be less likely to participate in 


\begin{tabular}{|c|c|c|c|c|}
\hline & \multicolumn{4}{|c|}{ Level and severity (AIS classification) of spinal cord injury } \\
\hline & $C 4 A B C(\mathrm{n}=3)$ & $C 5-C 8 A B C(\mathrm{n}=41)$ & $T H 1-S 5 A B C(\mathrm{n}=87)$ & $D E$ any level $(\mathrm{n}=34)$ \\
\hline Last SCI-focused examination (y); range; mean (s.d.) & $5-19$ & $0-37 ; 9(9)$ & $0-38 ; 13(10)$ & $1-34 ; 14(10)$ \\
\hline \multicolumn{5}{|l|}{ Satisfaction with the provided health services } \\
\hline Not important & - & - & 3 & 6 \\
\hline \multicolumn{5}{|l|}{ Does your GP know your $S C l$} \\
\hline Yes/No & $3 /-$ & $31 / 12$ & $74 / 2$ & $24 / 6$ \\
\hline I don't know & - & 4 & 5 & 3 \\
\hline \multicolumn{5}{|l|}{ How well is the GP's knowledge on SCl } \\
\hline \multicolumn{5}{|l|}{ How often do you see a doctor } \\
\hline Never/rarely & $-1-$ & $2 / 1$ & $4 / 7$ & $3 / 3$ \\
\hline Weekly/when necessary & -13 & -133 & $2 / 69$ & -127 \\
\hline \multicolumn{5}{|l|}{ Specialist consultation concerning SCl past 5 years } \\
\hline Neurologist Yes/No & $3 /-$ & $30 / 4$ & $64 / 18$ & $29 / 4$ \\
\hline Plastic surgeon Yes/No & -13 & $4 / 30$ & $6 / 76$ & -133 \\
\hline Urologist Yes/No & -13 & $4 / 30$ & $4 / 30$ & -133 \\
\hline Orthopedic surgeon Yes/No & $3 /-$ & $31 / 3$ & $76 / 3$ & $31 / 2$ \\
\hline \multicolumn{5}{|l|}{ How often do you see other healthcare providers } \\
\hline \multicolumn{5}{|l|}{ Physiotherapist } \\
\hline Weekly/when necessary & $2 /-$ & $9 / 10$ & $22 / 22$ & $8 / 6$ \\
\hline \multicolumn{5}{|l|}{ Nurse } \\
\hline Never/rarely & $2 /-$ & $14 /-$ & $61 / 4$ & $30 /-$ \\
\hline Weekly/when necessary & -11 & $16 / 5$ & $9 / 8$ & 271 \\
\hline \multicolumn{5}{|l|}{ Alternative medicine } \\
\hline Never/rarely & $3 /-$ & $34 /-$ & $74 / 1$ & $27 / 1$ \\
\hline When necessary & - & 1 & 6 & 4 \\
\hline \multicolumn{5}{|l|}{ Perceived lack of health service } \\
\hline Physio-/occupational therapy & $-1-$ & $2 / 2$ & $4 / 1$ & $2 / 1$ \\
\hline Psychologist/other & $-1-$ & -14 & $3 / 5$ & -14 \\
\hline Several services are lacking/services are complete & $-/ 1$ & $2 / 16$ & $6 / 32$ & $3 / 15$ \\
\hline
\end{tabular}

Abbreviations: AIS, ASIA Impairment Scale; ASIA, American Spinal Injury Association; GP, general practitioner; SCI, spinal cord injury.

Follow-up routines in 4 neurological subgroups of $\mathrm{SCl}$ based on recommendations from DeVivo et al. ${ }^{20}$. Values are given in range, mean, s.d. and absolute numbers (n).

population surveys; on the other hand, some eligible persons might be too busy to participate. The cross-sectional data reflect the respondents' situation at a certain point in time, and our retrospective questions might have introduced risk of recall bias as the participants were expected to report experiences from the past. Except for the GHQ-20, our questionnaire has limitations as it cannot be compared to other studies. Another concern is that the data collection took place in 2004/2005, and the reader must take into account that medical treatment and the health services have developed since then. However, based on our knowledge of the Norwegian healthcare services, we claim that the results of this study still are valid. Therefore, we argue that the data are valuable and contribute to the knowledge base of long-term SCI. The findings may be interesting for comparison to existing and future research results, and may also be part of the 
documentation when adjusting follow-up routines and long-term management of SCI.

SCI-user experiences with healthcare services need further investigation. All in all, we would claim the importance of 'SCI-trained' healthcare personnel ${ }^{39}$ and a need for studies on the effects of interventions that are meant to improve the services, measured on clinical outcomes, user satisfaction and resource use.

\section{CONCLUSIONS}

In a $20+$ years' post-injury SCI population, psychological distress is common and associated with the use of follow-up services. The varying satisfaction of people with SCI about healthcare services is notable, as is the finding that $20 \%$ of people with paraplegia did not use specific SCI follow-up services. The experiences of people with SCI with healthcare services need further investigation, and there is also a need for studies that examine the effects of interventions aimed at improving services and patient satisfaction.

\section{DATA ARCHIVING}

There were no data to deposit.

\section{CONFLICT OF INTEREST}

The authors declare no conflict of interest.

\section{ACKNOWLEDGEMENTS}

We thank the study participants, the Norwegian Association of the Disabled and the Norwegian Association for Spinal Injuries. Norwegian Foundation for Health and Rehabilitation (EXTRA), the Sunnaas Rehabilitation Hospital and the Eastern Norway Health Authority (Helse Øst) contributed with financial support to the project.

1 Svestkova O, Sladkova P, Kotkova K. Application of international classification of functioning, disability and health (ICF), functional health and disability. Cent Eur $J$ Public Health 2016; 24: 83-85.

2 Lidal IB, Hjeltnes N, Roislien J, Stanghelle JK, Biering-Sorensen F. Employment of persons with spinal cord lesions injured more than 20 years ago. Disabil Rehabil 2009; 31: 2174-2184.

3 Middleton JW, Lim K, Taylor L, Soden R, Rutkowski S. Patterns of morbidity and rehospitalisation following spinal cord injury. Spinal Cord 2004; 42: 359-367.

4 McColl MA, Aiken A, McColl A, Sakakibara B, Smith K. Primary care of people with spinal cord injury: scoping review. Can Fam Physician 2012; 58: 1207-1216 e626-35.

5 Dryden DM, Saunders LD, Rowe BH, May LA, Yiannakoulias N, Svenson LW et al. Utilization of health services following spinal cord injury: a 6-year follow-up study. Spinal Cord 2004; 42: 513-525.

6 Stillman MD, Frost KL, Smalley C, Bertocci G, Williams S. Health care utilization and barriers experienced by individuals with spinal cord injury. Arch Phys Med Rehabil 2014; 95: 1114-1126.

7 Osteraker AL, Levi R. Indicators of psychological distress in postacute spinal cord injured individuals. Spinal Cord 2005; 43: 223-229.

8 Craig A, Nicholson Perry K, Guest R, Tran Y, Dezarnaulds A, Hales A et al. Prospective study of the occurrence of psychological disorders and comorbidities after spinal cord injury. Arch Phys Med Rehabil 2015; 96: 1426-1434.

9 Schonenberg M, Reimitz M, Jusyte A, Maier D, Badke A, Hautzinger M. Depression, posttraumatic stress, and risk factors following spinal cord injury. Int J Behav Med 2014; 21: 169-176.

10 Lundin A, Hallgren M, Theobald H, Hellgren C, Torgen M. Validity of the 12-item version of the General Health Questionnaire in detecting depression in the general population. Public health 2016; 136: 66-74.
11 Gale CR, Harris A, Deary IJ. Reaction time and onset of psychological distress: the UK Health and Lifestyle Survey. J Epidemiol Commun Health 2016; 70: 813-817.

12 Burvill PW, Knuiman MW. Which version of the General Health Questionnaire should be used in community studies? Aust N Z J Psychiatry 1983; 17: 237-242.

13 Banks $\mathrm{MH}$. Validation of the General Health Questionnaire in a young community sample. Psychol Med 1983; 13: 349-353.

14 Anke AG, Stenehjem AE, Stanghelle JK. Pain and life quality within 2 years of spinal cord injury. Paraplegia 1995; 33: 555-559.

15 Lidal IB, Jensen AE, Larsen TW, Stanghelle JK. Fatigue in persons who have lived with spinal cord injury for $>20$ years. Spinal Cord 2013; 51: 103-108.

16 Lidal IB, Veenstra M, Hjeltnes N, Biering-Sorensen F. Health-related quality of life in persons with long-standing spinal cord injury. Spinal Cord 2008; 46: 710-715.

17 DeVivo M, Biering-Sorensen F, Charlifue S, Noonan V, Post M, Stripling T et al. International Spinal Cord Injury Core Data Set. Spinal Cord 2006; 44: 535-540.

18 Kirshblum SC, Burns SP, Biering-Sorensen F, Donovan W, Graves DE, Jha A et al. International standards for neurological classification of spinal cord injury (revised 2011). J Spinal Cord Med 2011; 34: 535-546.

19 Marino RJ, Barros T, Biering-Sorensen F, Burns SP, Donovan WH, Graves DE et al. International standards for neurological classification of spinal cord injury. J Spinal Cord Med 2003; 26: S50-S56.

20 DeVivo MJ, Biering-Sorensen F. New P, Chen Y. Standardization of data analysis and reporting of results from the International Spinal Cord Injury Core Data Set. Spinal Cord 2011: 49: 596-599.

21 Bratas 0, Gronning K, Forbord T. Psychometric properties of the Hospital Anxiety and Depression Scale and The General Health Questionnaire-20 in COPD inpatients. Scand J Caring Sci 2014; 28: 413-420.

22 Malt UF. The validity of the General Health Questionnaire in a sample of accidentally injured adults. Acta Psychiatr Scand Suppl 1989; 355: 103-112.

23 Bjordal K, Kaasa S. Psychological distress in head and neck cancer patients 7-11 years after curative treatment. Br J Cancer 1995; 71: 592-597.

24 Lidal IB, Snekkevik H, Aamodt G, Hjeltnes N, Biering-Sorensen F, Stanghelle JK. Mortality after spinal cord injury in Norway. J Rehabil Med 2007; 39: 145-151.

25 Kennedy P, Kilvert A, Hasson L. A 21-year longitudinal analysis of impact, coping, and appraisals following spinal cord injury. Rehabil Psychol 2016; 61: 92-101.

26 Ullrich PM, Lincoln RK, Tackett MJ, Miskevics S, Smith BM, Weaver FM. Pain, depression, and health care utilization over time after spinal cord injury. Rehabil Psychol 2013; 58: 158-165.

27 Noonan VK, Fallah N, Park SE, Dumont FS, Leblond J, Cobb J et al. Health care utilization in persons with traumatic spinal cord injury: the importance of multimorbidity and the impact on patient outcomes. Top Spinal Cord Injury Rehabil 2014; 20: 289-301.

28 Adriaansen JJ, Ruijs LE, van Koppenhagen CF, van Asbeck FW, Snoek GJ, van Kuppevelt $D$ et al. Secondary health conditions and quality of life in persons living with spinal cord injury for at least ten years. J Rehabil Med 2016; 48: 853-860.

29 Siddall PJ, Mclndoe L, Austin P, Wrigley PJ. The impact of pain on spiritual well-being in people with a spinal cord injury. Spinal Cord 2016; 55: 105-111.

30 Migliorini C, Callaway L, New P. Preliminary investigation into subjective well-being, mental health, resilience, and spinal cord injury. J Spinal Cord Med 2013; 36: 660-665.

31 Geyh S, Kunz S, Muller R, Peter C. Describing functioning and health after spinal cord injury in the light of psychological-personal factors. J Rehabil Med 2016; 48: 219-234.

32 Hartkopp A, Bronnum-Hansen H, Seidenschnur AM, Biering-Sorensen F. Suicide in a spinal cord injured population: its relation to functional status. Arch Phys Med Rehabil 1998; 79: 1356-1361.

33 Bauman WA, Spungen AM. Metabolic changes in persons after spinal cord injury. Phys Med Rehabil Clin N Am 2000; 11: 109-140.

34 Savic G, Short DJ, Weitzenkamp D, Charlifue S, Gardner BP. Hospital readmissions in people with chronic spinal cord injury. Spinal Cord 2000; 38: 371-377.

35 Hamilton R, Driver S, Noorani S, Callender L, Bennett M, Monden K. Utilization and access to healthcare services among community-dwelling people living with spinal cord injury. J Spinal Cord Med (e-pub ahead of print 25 May 2016; doi:10.1080/ 10790268.2016.1184828).

36 Bell N, Kidanie T, Cai B, Krause JS, Geographic variation in outpatient health care service utilization after spinal cord injury. Arch Phys Med Rehabil 2017; 98: 341-346.

37 Pannek J, Pannek-Rademacher S, Wollner J. Use of complementary and alternative medicine in persons with spinal cord injury in Switzerland: a survey study. Spinal Cord 2015; 53: 569-572.

38 Statistics Norway (Statistisk Sentralbyrå (SSB)). Available at: http://www.ssb.no/helse/ artikler-og-publikasjoner/helse-flere-velger-alternativt.

39 Charlifue S, Jha A, Lammertse D. Aging with spinal cord injury. Phys Med Rehabil Clin N Am 2010; 21: 383-402.

Supplementary Information accompanies this paper on the Spinal Cord website (http://www.nature.com/sc) 